\title{
Digitalização e acesso aberto na publicação em Ciências da Comunicação: o caso português*
}

\author{
Paulo Serra**
}

\section{Resumo}

A publicação é, sem dúvida, um dos imperativos básicos da ciência. A era digital veio tornar essa publicação cada vez mais fácil, barata e acessível. Nesse sentido, o artigo tem dois objetivos essenciais. O primeiro é o de descrever e avaliar a publicação portuguesa na área das Ciências da Comunicação no que se refere a fatores como a quantidade de materiais disponíveis online, a natureza desses materiais (digitais ou shovelware) e a sua acessibilidade (open access). Tendo como base essa descrição e avaliação do caso português, o texto tem como segundo objetivo proceder a algumas reflexões sobre a questão da internacionalização da publicação em língua portuguesa e as formas de contrariar a hegemonia da língua inglesa como língua franca da ciência.

Palavras chave: Publicação. Digitalização. Acesso Aberto. Ciências da Comunicação. Portugal.

\section{Digitization and open access on publication in Communication Sciences: the Portuguese case}

\section{Abstract}

Publishing is undoubtedly one of the basic requirements of science. In the digital era publishing has become increasingly easy, inexpensive and accessible. In this sense, the paper has two main objectives. The first is to describe and evaluate the Portuguese publication in the field of Communication Sciences with regard to factors such as the amount of material available online; the nature of these

* O texto constitui uma versão reformulada da intervenção no Painel "Panorama da difusão científica em Ciências da Comunicação e desafios da era digital", do 2ำ Fórum Integrado de Comunicação Ibero-americana (Confibercom), que teve lugar no ISMAI (Maia, Portugal), em 26-28 de maio de 2013. Conserva-se o português de Portugal.

** Professor doutor dos cursos de Pós-graduação em Ciências da Comunicação, Departamento de Comunicação e Artes, da Universidade da Beira Interior, Beira Interior - Portugal, e investigador do Laboratório de Comunicação Online (LabCom), do Instituto Coordenador da Investigação (ICI) - E-mail: pserra@ubi.pt 
materials (digital or shovelware) and accessibility (open access). Based on this description and evaluation of the Portuguese case, the second objective of the text is to make some reflections on the issue of internationalization of the publication in Portuguese language and the way to counter the hegemony of English as the lingua franca of science.

Keywords: Publication. Digitization.Open Access. Communication Sciences. Portugal.

\section{La digitalización y el acceso abierto a la publicación en Ciencias de la Comunicación: el caso portugués}

\section{Resumen}

La publicación es sin duda uno de los requisitos básicos de la ciencia. En la era digital esta publicación es cada vez más fácil, barata y accesible. En este sentido, el artículo tiene dos objetivos fundamentales. El primero es describir y evaluar la publicación portuguesa en el campo de Ciencias de la Comunicación con respecto a factores tales como la cantidad de material disponible en línea, la naturaleza de estos materiales (digital o shovelware) y la accesibilidad (acceso abierto). Tomando como punto de partida la descripción y evaluación del caso portugués, el segundo objetivo de este texto es hacer algunas reflexiones sobre el tema de la internacionalización de la publicación en portugués y las formas de combatir la hegemonía del inglés como lengua franca de la ciencia.

Palabras clave: Publicación. Digitalización. Acceso Abierto. Ciencias de la Comunicación. Portugal.

\section{Introdução}

$\mathrm{P}$ arece inegável que a ciência é, cada vez mais, uma tecnociência e uma ciência ao serviço da indústria (GARCIA; MARTINS, 2009). E, como tal, assente em grande parte na ideia de que "o segredo é a alma do negócio" - ou seja, na ideia de que também no campo da ciência os interesses privados e comerciais se podem sobrepor aos ideais humanísticos e emancipatórios que estão na origem daquela. Precisamente por isso - e contra isso - importa recuperar a palavra de ordem de Merton (1973) sobre o caráter comunista (comunalista), universalista, desinteressado e cético-organizado da ciência. Mesmo que o CUDOS ${ }^{1}$ já tenha

\footnotetext{
${ }^{1}$ Os imperativos da ciência apontados por Merton podem resumir-se na sigla CUDOS, "das primeiras letras das quatro normas (ou "imperativos institucionais", morais e técnicos): comunismo, universalismo, disinterestedness (não a falta de interesse, mas a isenção), organizedskepticism (ceticismo organizado) (GARCIA; MARTINS, p.97)”.
} 
dado lugar ao PLACE, ${ }^{2}$ os imperativos mertonianos devem continuar a ser defendidos como ideal normativo, como uma ideia no sentido kantiano do termo.

No que se refere especificamente ao "comunismo" da ciência, o princípio resume-se, para nós, numa fórmula muito simples: o que é pago pelo (dinheiro) público deve ser devolvido ao público - dando, assim, verdadeiro sentido à palavra publicar (de publicus, "relativo ao povo"). Como sublinha Merton (1973, p. 274) a propósito deste caráter "comunista" da ciência, "a conceção institucional da ciência como parte do domínio público está ligada ao imperativo da comunicação dos resultados [publicação]. O segredo é a antítese desta norma; a comunicação completa e aberta é imperativa". ${ }^{3}$ Pode-se mesmo fazer disso uma exigência de um programa político, como aconteceu recentemente com o "Partido Pirata" da Alemanha, que afirma no seu manifesto que "[...] no domínio da ciência, a atribuição de fundos deve ser condicionada à publicação livre do conhecimento obtido (acesso livre)" (PIRATEN PARTEI, 2012).

Com o advento da internet e da Web, em particular da Web 2.0, o imperativo de comunização - e comunicação - da ciência torna-se cada vez mais fácil e possível de realizar: tudo, praticamente tudo, pode ser produzido, distribuído e consumido digitalmente, a custos muito baixos; mesmo o que foi impresso antes da era digital pode ser agora digitalizado e disponibilizado sob a forma de shovelware.

É certo que a digitalização da ciência tem vindo a ser feita a passos largos - mas, de forma predominante, em língua inglesa e marcada pelos interesses comerciais de grandes companhias como a Thomson Reuters (ISI), a Elsevier (SCOPUS), a IGI Global e outras, que procuram fazer mais-valias privadas à custa do trabalho produzido com fundos públicos pelos cientistas das diversas universidades, laboratórios e centros de investigação - com a aquiescência mais ou menos resignada destes, submetidos ao impe-

\footnotetext{
2 "Proprietário, Local, Autoritário, Commissioned (no sentido de encomendado) e Especialista (GARCIA; MARTINS, 2009, p.100)".

${ }^{3}$ A tradução deste e doutros passos para português é da responsabilidade do autor.
} 
rativo do "publish or perish". O resultado desta verdadeira paródia do imperativo mertoniano da publicação da ciência é aquilo a que se tem vindo a chamar a "fast science", e que mais não é que uma caricatura da ciência - uma caricatura que, a mais ou menos curto prazo, não deixará de pôr em causa a própria qualidade da ciência.

É nossa posição que estas práticas podem/devem ser contrariadas através de uma dupla estratégia: por um lado, publicar tudo em regime de acesso aberto (open source), limitando os direitos autorais aos direitos morais; por outro lado, publicar em línguas que não o inglês, nomeadamente o português e o espanhol - contrariando também, deste modo, um certo imperialismo cultural que se pretende associar ao "universalismo" da ciência (FIDALGO, 2008; MARTINS, 2012). Pois o que este "universalismo" significa, na prática, é que quem não domina o inglês acaba por estar arredado, senão da leitura, pelo menos da publicação científica - que exige, em muitos casos, a proficiência de um native speaker (MENEGHINI; PACKER, 2007).

A própria dimensão de utilização do português e do espanhol na internet justifica a segunda das estratégias referidas. Com efeito, de acordo com dados recentes (INTERNET WORLD STATS, 2011; CHADE, 2013), o português é a quinta língua mais utilizada na internet, com cerca de 83 milhões de utilizadores. Por seu lado, o espanhol é a terceira língua mais utilizada, com cerca de 165 milhões. Juntas, as línguas portuguesa e espanhola - que somam cerca de 248 milhões de utilizadores - têm à sua frente apenas o inglês (com cerca de 565 milhões de utilizadores) e o chinês (com cerca de 510 milhões); ao que acresce uma margem de progressão bastante auspiciosa, se tivermos em conta a atual difusão da internet em países como o Brasil, Angola ou Moçambique, para nos referirmos apenas a alguns países de língua portuguesa.

Interessa, assim, descrever e avaliar a publicação portuguesa na área das Ciências da Comunicação no que se refere a fatores como a quantidade de materiais disponíveis online, a natureza desses materiais (digitais ou shovelware) e a sua acessibilidade (open access). Com essa finalidade, durante a primeira quinzena do mês de maio de 2013 levamos a efeito uma análise de conteúdo dos sí- 
tios Web dos elementos/entidades que se encontram mais ou menos diretamente envolvidos na publicação, a saber: Centros / Núcleos de Investigação; Revistas; Bibliotecas On-line; Editoras Digitais; Repositórios Científicos; Associações Científicas (SOPCOM). Os resultados dessa análise são apresentados nas secções seguintes.

\section{Centros / Núcleos de Investigação}

Em Portugal, os Centros / Núcleos de Investigação constituem os principais produtores e promotores da difusão científica na área das Ciências da Comunicação. Interessava, portanto, determinar o estado de digitalização e de acesso aberto em que cada um deles se encontrava, o que fizemos analisando as informações sobre publicação que apresentavam nas suas páginas Web. Incluímos, na nossa análise, o OBERCOM que, apesar de não ser propriamente um Centro / Núcleo de Investigação, tem vindo a desempenhar um importante papel nestedomínio ${ }^{4}$.

Considerámos, assim, os seguintes Centros / Núcleos de Investigação (seguimos a ordem por que são apresentadas na página Web da SOPCOM, em www.sopcom.pt, exceto o OBERCOM, que deixámos para o fim):

- CECL - Centro de Estudos de Comunicação e Linguagens (www.cecl.com.pt);

- CIMJ - Centro de Investigação Media e Jornalismo (www. cimj.org);

- CECS - Centro de Estudos de Comunicação e Sociedade (www.comunicacao.uminho.pt/cecs);

- CICANT - Centro de Investigação em Comunicação Aplicada, Cultura e Novas Tecnologias (http://cicant. ulusofona.pt);

- CETAC.MEDIA - Centro de Estudos das Tecnologias e Ciências da Comunicação (www.cetacmedia.org);

\footnotetext{
${ }^{4}$ Refira-se ainda que o Obercom tem como "Associados Honorários" o CIES-IUL - Centro de Investigação e Estudos de Sociologia, do Instituto Universitário de Lisboa, o LABCOM - Laboratório de Comunicação e Conteúdos Online, da Universidade da Beira Interior, e o CECS - Centro de Estudos de Comunicação e Sociedade, da Universidade do Minho; e, como "Parceiros", vários Observatórios e entidades universitárias nacionais e estrangeiras (incluindo os Centros de investigação já mencionados).
} 
- LABCOM - Laboratório de Comunicação e Conteúdos Online (www.labcom.ubi.pt);

- OBERCOM - Observatório da Comunicação (www. obercom.pt).

Os dados recolhidos relativamente a cada um dos Centros / Núcleos de Investigação permitem extrair as seguintes conclusões gerais:

- Os vários Centros / Núcleos de Investigação encontram-se em diferentes estados de digitalização e acesso aberto, que vão desde um mínimo do CICANT até um máximo do LABCOM e do OBERCOM.

- Vários dos Centros / Núcleos que apostam na digitalização continuam a apostar também no impresso, nomeadamente no que se refere aos livros, tendo mesmo ligação a editoras tradicionais (como é o caso do CECS ou do CIMJ). Isso faz com que, em regra, os livros dos investigadores só tenham disponível a informação de capa ou o índice; as exceções a esta regra são o CECS (que disponibiliza vários livros em formato digital) e o LABCOM (que disponibiliza todos os seus livros em formato digital).

- Com exceção do CECL, todos os Centros / Núcleos disponibilizam em parte (um) ou na totalidade (os restantes) os conteúdos das suas revistas, mesmo quando elas são impressas.

\section{Revistas}

Mesmo não aceitando a ideia, hoje corrente nalguns círculos das ciências mais "duras", mas não só, de que a publicação científica equivale à publicação emrevistas científicas, de preferência com fator de impacto ${ }^{5}$ e indexadas em bases de dados como a ISI (Thomson-

\footnotetext{
${ }^{5}$ Como refere Garfield (2006, p.90), "o fator de impacto de uma revista baseia-se em dois elementos: o numerador, que é o número de citações que, no ano em curso, são feitas a qualquer dos itens publicados na revista nos dois anos anteriores; e o denominador, o número de artigos substantivos (itens fonte) publicados nos mesmos dois anos."
} 
-Reuters) ou a SCOPUS (Elsevier), parece inegável a importância que as revistas assumiram como meio de publicação científica logo desde a fundação do Journal des Sçavans e do Philosophical Transactions, ambos em 1665 (BANKS, 2009; GARFIELD, 1979).

Não admira, assim, que cada um dos Centros / Núcleos de Investigação que acabamos de referir publique também a sua revista - e, por vezes, mais do que uma, como acontece com o CECL ou o LABCOM. No entanto, o universo das revistas de Ciências da Comunicação em Portugal não se reduz às revistas dos Centros / Núcleos de Investigação. Assim, e para objeto da nossa análise, conseguimos identificar 14 revistas relevantes nesta área (indica-se, para cada uma delas, o nome e o Centro/Unidade de Investigação ou a Instituição de Ensino Superior que a edita):

- Caleidoscópio: Revista de Comunicação e Cultura - CICANT;

- Comunicação e Sociedade - CECS;

- Comunicação Pública-ESCS (Escola Superior de Comunicação Social, Lisboa);

- DOC Online. Revista Digital de Cinema Documentário LABCOM e UNICAMP (Brasil);

- Estudos em Comunicação - LABCOM;

- Interact: Revista Online de Arte, Cultura e Tecnologia - CECL;

- Media EJ Jornalismo - CIMJ;

- Obs (Observatório) - OBERCOM;

- prisma.com - CETAC.MEDIA;

- Revista Comunicação E Cultura - CECC (Centro de Estudos de Comunicação e Cultura) - UCP (Universidade Católica Portuguesa, Lisboa);

- Revista Comunicando - SOPCOM (Associação Portuguesa de Ciências da Comunicação) - GT Jovens Investigadores;

- Revista de Comunicação e Linguagens - CECL;

- Revista Estudos de Jornalismo - SOPCOM - GT de Jornalismo e Sociedade;

- Trajectos: Revista de Comunicação, Cultura e Educação ISCTE (Instituto Superior de Ciências do Trabalho e da Empresa). 
Durante muitos anos, o panorama das revistas de Ciências da Comunicação em Portugal resumiu-se à Revista de Comunicação e Linguagens, do CECL, fundada em 1985. No entanto, a partir de 1999, ano em que é criada a revista Comunicação e Sociedade, pelo CECS - ou seja, catorze anos depois - são criadas as restantes 13 revistas, o que dá uma média de cerca de uma por ano. A essa dinâmica está ligado não só o aparecimento dos novos cursos de Ciências da Comunicação mas, sobretudo, a criação e funcionamento dos Centros / Núcleos de Investigação referidos atrás.

Todas as revistas publicam em português, mas poucas - apenas três $(21,4 \%)$ publicam exclusivamente em português. A maior percentagem das revistas (36\%, ou seja, cinco) publica artigos monolingues em português, espanhol e inglês, seguindo-se o grupo das que publicam em português, espanhol, inglês e francês (dois, isto é, $14,3 \%)$.

Nos resumos, o que ressalta é a utilização do inglês, a par das línguas em que os originais são escritos, o que acontece em dez (71\%) dos casos - algo que terá a ver com a procura de uma maior visibilidade internacional e, quiçá, a possibilidade de indexação em bases de dados de revistas.

A opção pelo digital, que pareceria natural nos tempos que correm, ainda não é clara, com um total de sete revistas (50\%) a optarem por este formato - ainda que uma delas também envolva a impressão - e outras sete (50\%) a optarem exclusivamente pelo impresso. Das 14 revistas, nove (64\%) disponibilizam totalmente o seu conteúdo online, sendo que as outras cinco (36\%), ou não disponibilizam nada (duas), ou disponibilizam apenas os resumos (duas), ou disponibilizam apenas parte do conteúdo (uma).

Das 14 revistas, $11(78,6 \%)$ optam pela periodicidade semestral, optando as outras três por uma periodicidade trimestral, quadrimestral e anual (ainda que uma das que referem periodicidade semestral tenha tido até agora, de facto, periodicidade anual).

Há sete revistas (50\%) que não estão indexadas em catálogos e/ou bases de dados. Das restantes sete que estão indexadas, seis estão na Latindex e uma está na Latindex e na SCOPUS (Elsevier). Não há nenhuma revista indexada na ISI (Thomson Reuters), 
seja no Social Sciences Citation Index, seja no Arts and Humanities Citation Index.

\section{Bibliotecas online}

Nesta matéria, a grande referência na área das Ciências da Comunicação em Portugal é a BOCC - Biblioteca Online de Ciências da Comunicação (www.bocc.ubi.pt), que foi fundada em maio de 1999 por António Fidalgo, ficando alojada nos servidores da Universidade da Beira Interior (UBI). Atualmente encontra-se integrada, como um dos seus projetos pioneiros, no LABCOM. Todos os seus textos, formatados em LaTeX, são de acesso livre.

Em 16 de maio de 2013, a BOCC incluía um total de 3441 textos (artigos, ensaios, monografias, dissertações, teses etc.), em português (maioritariamente), espanhol e inglês, correspondendo a 2180 autores, oriundos de 205 instituições de ensino superior portuguesas, brasileiras, espanholas e dos EUA.

Entre 1 de junho de 2012 e 15 de maio de 2013 (11 meses e meio), a BOCC teve um total de 604.877 visitas, correspondendo a uma média mensal de 52.598 (cálculo para 11,5 meses) e diária de 1742 visitas - sendo que a maior parte dos visitantes tem origem no Brasil.

\section{Editoras digitais}

Neste domínio merece especial relevo a experiência dos Livros Labcom (www.livroslabcom.ubi.pt/), iniciada já há alguns anos. Os livros, que são objeto de análise por peer-reviewers, são depois formatados em LaTeX pela equipa daquela unidade de investigação. No momento em que escrevemos, a editora disponibiliza 93 livros para descarga livre em pdf e, mais recentemente,em e-pub - mas que também podem ser encomendados como livros impressos, devendo nesse caso ser pagos.

Refira-se, ainda, que entre 1 de junho de 2012 e 15 de maio de 2013 (11,5 meses), a Livros Labcom teve um total de 91780 visitas, o que perfaz uma média mensal de 7981 e diária de 266 visitas. 


\section{Repositórios científicos}

Pese embora o facto de cada instituição do ensino superior ter o seu próprio Repositório de artigos científicos, teses e dissertações e comunicações em conferências etc., incluindo os da área das Ciências da Comunicação, merece aqui especial destaque o RCAAP - Repositório Científico de Acesso Aberto de Portugal (www.rcaap.pt/). De acordo com a informação da Fundação para a Computação Científica Nacional, o RCAAP "tem por missão promover, apoiar e facilitar a adopção do movimento de acesso aberto ao conhecimento científico em Portugal ${ }^{6}$ ". De acordo ainda com a informação da FCCN, em setembro de 2012 o RCAAP ultrapassava já os cem mil documentos, agregados a partir de 36 repositórios de instituições de ensino e investigação e cinco revistas científicas, todos nacionais.

\section{Associações científicas}

Aqui referimo-nos, especificamente, à SOPCOM, a Associação Portuguesa de Ciências da Comunicação. Para além de alojar duas revistas de dois dos seus Grupos de Trabalho (ver atrás), o sítio Web da SOPCOM (www.sopcom.pt), na rubrica "Eventos anteriores", inclui três das atas dos seus sete congressos, prevendo-se para breve a disponibilização das restantes.

\section{Considerações finais}

Sem querermos cair na conhecida lógica do copo meio cheio ou meio vazio, diremos que o estado da publicação científica portuguesa na área das Ciências da Comunicação ${ }^{7}$ em matéria de digitalização e acesso livre, não sendo o ideal, está, no entanto, longe de ser mau. Se utilizássemos uma escala de um a cinco - com

\footnotetext{
${ }^{6}$ Site da FCCN. Consultado em 15 de maio de 2013, em http://www.fccn.pt/pt/ servicos/conhecimento-e-arquivo/repositorio-cientifico-rcaap ${ }^{7}$ Que, obviamente, não inclui a publicação dos cientistas portugueses em meios de comunicação científica (nomeadamente revistas) estrangeiros.
} 
um a significar o mínimo e cinco o máximo -, classificá-lo-íamos, certamente, no nível quatro. Neste aspecto, a publicação científica portuguesa na área das Ciências da Comunicação acompanha uma tendência que, iniciada nos finais dos anos 90 do século 20, não deixará, certamente, de se aprofundar no futuro próximo - em virtude de razões não apenas académicas mas também económicas e políticas; e não apenas no que se refere a revistas científicas, mas também a livros. Obviamente que, para além da sua dimensão mais otimista, um tal processo não deixa de colocar todo um conjunto de problemas epistemológicos, éticos e políticos, sobre os quais urge refletir (HALL, 2008).

Outra questão, diferente, e já colocada por Moisés de Lemos Martins (2012), será a de sabermos se este estado de digitalização e de acesso livre das publicações acima da média corresponderá a um estado de internacionalização também acima da média - uma questão à qual não podemos deixar de responder negativamente. Com efeito, excluindo o Brasil, e mesmo aí apenas no que se refere a algumas publicações e alguns autores, não nos parece que a investigação portuguesa tenha já penetrado de forma significativa quer em países de língua portuguesa quer em países de língua espanhola - algo que se pode verificar pela reduzida taxa de citações de autores e publicações portugueses que existe na literatura publicada nesses países (isto mesmo se, na falta de indicadores estatísticos, tiramos esta conclusão apenas com base na nossa experiência pessoal de leitor regular dessa literatura). O mesmo acontece, obviamente, no que se refere à penetração, em Portugal, da investigação produzida no Brasil ou outros países de língua portuguesa e em países de língua espanhola - quando muito, conhecem-se traduções brasileiras ou espanholas de autores americanos, ingleses ou franceses.

$\mathrm{O}$ caso torna-se ainda mais crítico quando se fala da penetração da investigação portuguesa em Ciências da Comunicação nos países de língua inglesa. Mesmo quando ela é traduzida para inglês, dificilmente o autor / tradutor possui as competências linguísticas de um native speaker, consideradas pelos editores como requisito mínimo; ao que acresce que também dificilmente as investigações 
de caráter local e cultural, como são muitas das produzidas na área das Ciências da Comunicação, interessam ao público potencial das publicações em inglês (pelo menos na perceção dos seus editores).

Mas não se pense que esta questão se refere, exclusivamente, à ciência produzida em Portugal, ou apenas à produzida na área das Ciências da Comunicação. Assim, referindo-se à situação do Brasil há alguns anos atrás, Meneghini e Packer (2007, p.114), calculavam que, dos cerca de 50 mil artigos publicados anualmente pelos cientistas brasileiros, maioritariamente em português (60\%), apenas $18 \mathrm{mil}(36 \%)$ correspondiam a revistas indexadas pela base de dados Web of Science (da Thomson Reuters), sendo aqui a percentagem de artigos em português de apenas 2,7\%. A Web of Science é, assim, na prática, uma English Web of Science.

Ora, como se sabe, a suposta "inevitabilidade" do inglês como língua franca da ciência não tem a idade da ciência moderna. De fato, ela data apenas do pós-II Guerra Mundial - até lá, e desde o iluminismo, o francês e o alemão eram maioritários, depois dos vários séculos em que o latim imperou (FORATTINI, 1997). A opção por - a imposição de - uma língua franca em vez de outra não é, portanto, uma questão "natural": ela traduz, de facto, a hegemonia económica, política e militar de uma região do globo sobre outras. Daí a necessidade de contrariar a hegemonia global (do inglês) com contra-hegemonias locais, nomeadamente a do português (CABRAL, 2007).

Havendo meios materiais e humanos para isso, parece-nos - e aqui seguimos Forattini (1997, p.7) - que a forma ideal de contrariar a hegemonia do inglês seria a existência de publicações trilingues, com todos os seus artigos e resumos escritos simultaneamente em português, espanhol e inglês - o que seria apenas mais um passo em relação às publicações bilingues, em português e inglês, que hoje já existem, nomeadamente no Brasil, onde a Brazilian Journalism Researche a e-compós são dois exemplos conhecidos. Voltando novamente aos números referentes à presença das diversas línguas na internet, teríamos assim um público potencial de cerca de 813 milhões de utilizadores $(83$ milhões de falantes de português, 165 de espanhol e 565 de inglês), muitos mais que 
os cerca de 510 milhões de utilizadores de língua chinesa. Reconhecemos, no entanto, que uma tal proposta exige meios materiais e humanos profissionalizados e relativamente caros que, neste momento, a maior parte dos Centros / Núcleos de Investigação portugueses atrás mencionados não possui, sendo que a maior parte dos trabalhos de publicação que aí é feita o é em regime de voluntariado e pro bono.Todavia, é possível que, num futuro próximo, ferramentas de tradução automáticas cada vez mais aperfeiçoadas contribuam, de forma decisiva, para faciltar este desiderato - e permitir, mesmo, a existência de uma outra Babel sem novas línguas francas (OSTLER, 2010). Na (por enquanto) impossibilidade prática de publicações trilingues, a inclusão nas publicações científicas em português de artigos e resumos em línguas que não o português - nomeadamente em espanhol e em inglês - parece ser uma forma acertada de lutar contra a tendência para a invisibilidade, e de procurar atingir públicos mais amplos. Esta é, precisamente a via já seguida por revistas como a Intercom, e que deveria generalizar-se.

\section{Referências}

BANKS, David. Starting science in the vernacular: notes on some early issues of the Philosophical Transactions and the Journal des Sçavans, 1665-1700, 2009.

ASp, n. 55, p. 5-22, 2009.Disponível em: < http://asp.revues.org/213>. Acesso em: 29 agos 2012 .

CABRAL, João de Pina, Língua e hegemonia nas ciências sociais. Análise Social, v. XLII, n. 182, p. 233-7, 2007.

CHADE, Jamil. Português é 5a língua mais usada na web. O Estado de S. Paulo,S. Paulo, 14 maio 2013. Disponível em: < http://www.estadao.com.br/ noticias/impresso,portugues-e-5-lingua-mais-usada-na-web-, 1031475,0.htm >. Acesso em: 16 maio 2013.

FIDALGO, António. As línguas ibéricas face à informação global. In:GOMÉZ, Francisco Xavier (Org.). Comunicación y desarrollo cultural en la Península Ibérica. Sevilha: Universidad de Sevilla, 2008. p. 43-54

FORATTINI, Oswaldo Paulo. A língua franca da ciência. Revista de Saúde Pública, S. Paulo, v.31, n.1, p. 3-8, fev. 1997. 
GARCIA, José Luís;MARTINS, Hermínio.O ethos da ciência e suas transformações contemporâneas,com especial atenção à biotecnologia. Scientiæ Zudia, São Paulo, v. 7, n. 1, p. 83-104, 2009.

GARFIELD, Eugene. Citation indexing: its theory and application in science, technology, and humanities. New York: John Wiley \& Sons, 1979.

GARFIELD, Eugene. The history and meaning of the journal impact factor, JAMA, v.295, n.1, p. 90-3, jan. 2006. Disponível em: <http://garfield.library. upenn.edu/papers/jamajif2006.pdf > . Acesso em: 18 maio 2013.

HALL, Gary. Digitize this book! The politics of new media, or why we need open access now. Minneapolis: University of Minnesota Press, 2008.

INTERNET WORLD STATS. Internet world users by language: top 10 languages. 31 maio 2011.Disponível em: <http://www.internetworldstats.com/ stats7.htm >. Acesso em: 17 maio 2013.

MARTINS, Moisés de Lemos. Revistas científicas de ciências da comunicação em Portugal: da divulgação do conhecimento à afirmação do Português como língua de pensamento. Intercom - RBCC, São Paulo, v.35, n.1, p. 233-251, jan./jun. 2012.

MENEGHINI, Rogerio; PACKER, Abel L. Is there science beyond English? EMBO- European Molecular Biology Organization reports, v.8, n.2, p. 112 116, fev. 2007. Disponível em: <http://www.nature.com/embor/journal/v8/n2/ pdf/7400906.pdf>. Acesso em: 18 maio 2013.

MERTON, Robert. The normative structure of science, In: The sociology of science: theoretical and empirical investigations. Chicago: University of Chicago Press, 1973, p. 267-278.

OSTLER, Nicholas. The last lingua franca: English until the return of Babel. New York: Walker \& Company, 2010.

PIRATEN PARTEI. Manifesto of the Pirate Party of Germany (English Version). April 10 maio 2012. Disponível em: <http://www.piratenpartei.de>. Acesso em: 17 maio 2013.

\section{J. Paulo Serra}

Licenciado em Filosofia pela Faculdade de Letras de Lisboa e mestre e doutor em Ciências da Comunicação pela Universidade da Beira Interior, Covilhã (Portugal). Autor dos livros Informação e sentido. O Estatuto Epistemnológico da Informação; A Informação como utopia; e Manual de Teoria da Comunicação, entre outros. 